\title{
Brief Mating Behavior at Dawn and Dusk and Long Nocturnal Matings in the Butterfly Melanitis leda
}

\author{
Freerk Molleman $(\mathbb{D} \cdot$ Sridhar Halali $(\mathbb{D} \cdot$ Ullasa \\ Kodandaramaiah
}

Received: 6 March 2020 / Revised: 30 July 2020 / Accepted: 2 August 2020 / Published online: 15 September 2020

(C) The Author(s) 2020

\begin{abstract}
Information on the mating system of an insect species is necessary to gain insight into sexual selection and population structure. Male territoriality of the common evening brown butterfly Melanitis leda has been studied in the wild, but other aspects of its mating system remain largely unknown. For a population of M. leda in South India, we observed male-male and male-female interactions in captivity, measured mating duration and spermatophore mass, and also determined the degree of polyandry in the wild. We found that mating behavior takes place for short periods of time around dawn and dusk. Our observations corroborate that males compete in aerial combats (twirling) and interfere with mating pairs. In the morning, they may use shivering to warm up.
\end{abstract}

Electronic supplementary material The online version of this article (https://doi.org/10.1007/s10905-020-09753-x) contains supplementary material, which is available to authorized users.

\section{F. Molleman $(\bowtie)$}

Department of Systematic Zoology, Institute of Environmental Biology, Faculty of Biology, Adam Mickiewicz University in Poznan, Ul. Uniwersytetu Poznańskiego 6, Poznań PL-61-614, Poland

e-mail: fremol@amu.edu.pl

S. Halali

Department of Zoology, University of Cambridge, Downing Street, CB2 3EJ Cambridge, UK

\section{U. Kodandaramaiah $(\bowtie)$}

IISER-TVM Centre for Research and Education in Ecology and Evolution (ICREEE), School of Biology, Indian Institute of Science Education and Research Thiruvananthapuram, Kerala, India

e-mail: ullasa@iisertvm.ac.in
Females can twirl with males and refuse mating by pointing their abdomens upwards or by flying away. Males court females by fluttering their wings while perched behind females, and then initiate copulation by curling their abdomens ca. 180 degrees sideways to make genital contact. While in the morning, matings lasted on average one hour and twenty-three minutes and never exceeded three hours, in the evening, matings could be of similar duration, but $42 \%$ of butterflies only separated when dawn was approaching. However, such long nocturnal matings did not result in heavier spermatophores. The first spermatophore of a male tended to be larger than subsequent spermatophores. Together with previous studies on this species, our findings suggest that males compete mainly through territorial defense (as reported before), courtship performance, and interference, and to a lesser extent by providing spermatophores, while females exert some control over the mating system by the timing of their receptivity and mate choice.

Keywords Aerial combat - Circadian rhythm . Courtship · Interference competition · Mating duration . Mating territory $\cdot$ Spermatophore

\section{Introduction}

The mating system of insects affects sexual selection and sex differences, as well as population structure (Andersson 1994). Therefore, insight into the mating system is important for understanding an insect's biology. Mating systems can be divided into components that 
follow each other in time, such as timing of mating behavior, strategies to find mates, competition for potential mates, courtship, mate choice, sperm competition, and investment in offspring (Pliske 1975; Andersson 1994; Andersson and Simmons 2006; Shuker and Simmons 2014).

Variation among butterfly species in mating system traits can provide insight into the evolution of traits such as sexual dimorphism and life span (Wickman 1992; Wiklund et al. 2003; Allen et al. 2011; Cannon 2019). Butterfly mating systems often include diel patterns in mating behavior (Freitas et al. 1997), males defending territories through aerial combat such as twirling (Rutowski 1991; Kemp and Wiklund 2001), females signaling receptivity (Rutowski 1980; Bergman et al. 2011), male courtship such as hovering behind females and wing fluttering (Mitra et al. 2016), female and male mate choice (Kemp 2007; Costanzo and Monteiro 2007), mating interference by other males (Pliske 1975; Kemp 2002), transfer of large spermatophores that contain nutrients (Boggs and Gilbert 1979; Oberhauser 1989; Bissoondath and Wiklund 1995), and sperm competition (Watanabe 2016). There is much variation among butterfly species in these traits (Cannon 2019). For example, closely related species may avoid reproductive interference through divergent diel activity patterns (DeVries et al. 2008), butterflies vary from monandrous to highly polyandrous (Karlsson 1995; Molleman et al. 2005), and spermatophores can vary from tiny to representing a large proportion of male body mass (Oberhauser 1988; Bissoondath and Wiklund 1995; Karlsson 1998; Molleman et al. 2005).

Mating systems can also vary within butterfly species. There may be variation among populations (Välimäki and Kaitala 2006), within populations (Wedell et al. 2002; Molleman et al. 2004), and across seasons (Prudic et al. 2011). Therefore, information on mating system traits from different regions and seasonal forms can shed further light on the biology of a butterfly species.

In butterflies, information on the degree of polyandry and spermatophore size is important to understand their mating systems. Butterfly spermatophores can contain nutrients such as amino acids and sodium that enhance the female's reproductive output and can thus be regarded as paternal investment (Boggs and Gilbert 1979; Pivnick and McNeil 1987; Oberhauser 1988, 1989; Bissoondath and Wiklund 1995; Mitra et al. 2016). Therefore, females may be selected to mate multiply to "forage" for these nutrients (Kaitala and Wiklund 1994a, b). Males in turn can delay remating of the female with other males by providing a large spermatophore so that the female has no incentive to forage for these nutrients by mating with other males (Boggs 1981; Oberhauser 1992; Kaitala and Wiklund 1994a, b). Males of polyandrous species tend to produce larger spermatophores compared to those of monandrous species in which males do not compete by providing larger spermatophores (Bissoondath and Wiklund 1995). When females mate multiply, males also have on average more opportunities to mate multiply, which combined with large spermatophores in such polyandrous species, increases overall investment into spermatophores. Males may have a strategy to invest a larger proportion of their resources in their first mating or to spread nutrients more evenly over subsequent matings (Svärd and Wiklund 1986; Wedell et al. 2002; Molleman et al. 2004). One may expect that when more nutrients are transferred, the mating lasts longer because nutrient transfer takes time (Rutowski and Gilchrist 1985). However, in subsequent matings of individual males, smaller spermatophores may be produced during longer matings compared to first matings of these males (Rutowski and Gilchrist 1985; Bissoondath and Wiklund 1996; Molleman et al. 2004), indicating difficulty in producing consecutive spermatophores. Therefore, information on female and male mating frequency, spermatophore size, and mating duration is key for understanding butterfly mating systems.

Here, we investigate the mating system of the Common Evening Brown butterfly (Melanitis leda; Nymphalidae: Satyrinae). Melanitis leda is widely distributed in the Old World tropics (Larsen 1991; Kunte 2000). It is mainly active in the early morning and in the evening, and adults feed on rotting fruits (Larsen 1991). The ventral wing surface shows striking seasonal polyphenism, where wet season forms have a series of conspicuous marginal eyespots, while dry season forms have a cryptic wing pattern which is polymorphic (Brakefield 1987). Although some naturalists have noted M. leda mating behavior around both sunrise and sunset (Common and Waterhouse 1981), others report that mating behavior is restricted to sunset (Parsons 1999; Kemp 2002), possibly indicating geographic variation in this trait. Kemp $(2002,2003)$ described how just before sunset, males engage in contest behavior where they perch on the vegetation, defend a territory, and pursue females that fly high above the vegetation, 
contrasting against the sky. A single direct observation of an interaction with a female showed that two males can pursue a single female, and thus interfere with each other (Kemp 2002).

To determine the timing of mating behavior, and to detect patterns in mating duration and spermatophore size, we observed mating behavior in outdoor cages, measured mating duration, and weighed spermatophores in a South Indian population of M. leda. In particular, we tested hypotheses on relationships between spermatophore size and mating duration, and for these two parameters separately whether they are predicted by the timing of the mating (sunrise or sunset), the seasonal form of the male, the size of the male, and the mating history of the male. We also made observations on the ethology of interactions between competing males and between males and females that would be hard to obtain in the wild, and counted spermatophores in wild butterflies.

\section{Methods}

\section{Butterfly Rearing}

Wild females were collected from Thiruvananthapuram, Kerala, India, and allowed to lay eggs on maize seedlings. Most larvae were reared on maize seedlings in outdoor cages which yielded wet season- and intermediate adult forms. In addition, some larvae were reared on a range of grasses in sleeves inside a growth chamber at $24^{\circ} \mathrm{C}$ and $55 \%$ Relative Humidity as part of another experiment (see Molleman et al. 2020), which yielded all seasonal forms (wet, dry, and intermediate phenotypes; Halali et al. 2019). All pupae were sexed and weighed 1-3 days after pupation (Sartorius MSA6.6 s-000-DM) nearest up to $0.0001 \mathrm{mg}$. They were kept individually in upside down plastic jars with tissue paper at the bottom (fixed between the jar and the lid), and paper lining on the sides. Eclosed butterflies were marked with a unique number using a permanent marker and released into experimental cages 2-4 days after eclosion.

\section{Experimental Arena and Procedures}

We performed multiple pilot trials in which we made observations only during the evening. These trials revealed that (1) M. leda does not readily couple in small cages (height $50 \mathrm{~cm}$, length $50 \mathrm{~cm}$, width $30 \mathrm{~cm}$ ), because this species requires a large space for courtship flights, (2) when male densities are high, interference between males disrupts courtships and few matings occur (similar to Pliske 1975), (3) before starting mating trials, acclimatization of females is necessary for at least five hours to obtain mating pairs, and (4) matings can last till shortly before dawn.

Butterflies were released into large outdoor cages of ca. $2.2 \mathrm{~m}$ height width and length $\left(10.6 \mathrm{~m}^{3}\right.$; example shown in supplement 1$)$. Cages were covered on all four sides and the ceiling with shade netting (75\%) and were sheltered by transparent polycarbonate sheets on the roof. We kept some plants for shelter, and mashed banana and water for food and drink inside the cages. To allow females to get acclimatized to the cage environment, they were released at least five hours prior to the start of the experiments. Once released, both females and males remained inside the cages throughout trials. Because females were killed to determine spermatophore mass, whereas males were returned to obtain subsequent matings, the sex ratio tended to become male biased. However, we compensated for this by adding young virgin females (but not males) to obtain subsequent matings from the same males. The density in the trials reported here was kept between 10 and 30 individuals. Even though this is a much higher density than found in the wild, it was suitable for observing many interactions and obtaining matings. Four trials were conducted in 2016; from 21 to 23 October, 1119 November, 25-28 November, and 3-29 December; respectively. The experiment was conducted near the equator where the timing of dawn and dusk remains similar throughout the year (e.g. in October sunrise is at around 6:10 and sunset at around 18:10, while in December sunrise is at around 6.25 and sunset at around 18:05).

Observations were started in the morning before butterflies became active $(\sim 5: 45)$ and lasted until the end of mating activity $(\sim 7: 00)$. Similarly, in the evenings, observations were initiated before the start of mating activity $(\sim 17: 30)$ and lasted until the end of mating activity $(\sim 19: 00)$. Frequent observations carried out during the day did not provide any evidence for the occurrence of mating behavior or mating pairs. During observations, an observer sat on a chair in a corner inside the cage with a flashlight to intermittently spot mating pairs when it was dark. This did not appear to affect butterfly activity. Each couple was gently picked 
up by holding the wings of both the male and female simultaneously between index and middle finger, and was thus transferred to a small numbered cage (diameter $19 \mathrm{~cm}$, height $30 \mathrm{~cm}$ ). This did not disrupt matings.

The small cages containing the coupled mating pairs were observed directly or through recorded videos to obtain data on mating duration. Notably, mating durations were often longer than could be recorded on the camera memory (about $6 \mathrm{~h}$ ), and butterflies were typically first observed directly, before the recording was started. Therefore, the duration of long matings were often underestimated when they exceeded seven hours. After de-coupling, females were stored at $-20^{\circ} \mathrm{C}$ for later dissections to measure spermatophore size, while males were released back into the experimental cage. When female abdomens were too dry to carry out dissections, the abdominal tissues were re-hydrated by placing them on wet cotton wool covered with tissue paper in a closed plastic box overnight. After dissections, spermatophores were air dried for $48 \mathrm{~h}$ before measuring the dry mass on a microbalance (Sartorius MSA6.6 s-000-DM) nearest up to $0.0001 \mathrm{mg}$. Unfortunately, mating duration was not available for 19-28 November and spermatophore size data from 3 to 21 December due to technical issues, which limited our power to link mating duration to spermatophore mass.

Female mating frequency in the wild was estimated by dissecting field caught females irrespective of age class (Burns 1968). Samples were collected by placing fruit-baited traps in Thiruvananthapuram, South India, from February 2016 to August 2017.

\section{Statistical Analyses}

Data were analyzed using t-tests, ANOVA, regression, and GLM models after checking for normality of residuals using Q-Q plots in Statistica (TIBCO 2017), and graphs were prepared in R (R Core Team 2017). See details in "Results" section.

\section{Results}

\section{Timing of Mating Behavior}

A total of 99 couplings were recorded across all four trials. Twenty-three couplings were with males of dry season forms, 40 with intermediate, and 13 with wet season forms (22 were unassigned). Melanitis leda showed mating activity strictly around sunset and sunrise, and only for a brief period of time. More couplings occurred in the evening $(\mathrm{N}=72)$ than in the morning $(\mathrm{N}=27$; Fig. 1). In the morning, both the first and the last coupling commenced on average at $6: 15$, the earliest was at $6: 00$, the latest at $6: 22$. The average time between the first and last coupling during a given morning was $5 \mathrm{~min}$, and the maximum was 9 min (only 3 mornings with more than 1 mating). In the evening, the first coupling commenced on average at 18:10 and the last on average at 18:16, the earliest was at $17: 53$ and the latest at 18:50. The average time between the first and the last coupling during a given evening was $10 \mathrm{~min}$ and the maximum was $50 \mathrm{~min}(\mathrm{~N}=19$ days with more than one coupling in the evening).

\section{Mating Duration and Spermatophore Size}

We obtained mating duration information for 77 couplings, and weighed 40 spermatophores. Male re-mating frequency was high, with males mating up to 5 times (Fig. 1). Males were able to mate in quick succession. For example, 4 males mated both in the morning and evening of the same day. Mating duration had a bimodal distribution with maxima around $2 \mathrm{~h}$ and around $9 \mathrm{~h}$, while matings that lasted between 3 and $6 \mathrm{~h}$ were relatively rare (Fig. 1). Most matings lasted between 1 and $3 \mathrm{~h}$ ( $58 \%$ of matings $\mathrm{N}=77$ ). While mating duration in the morning ranged between $50 \mathrm{~min}$, and $2 \mathrm{~h}$ and $36 \mathrm{~min}$ with an average of $1 \mathrm{~h}$ and $23 \mathrm{~min}$, evening matings often ended only shortly before sunrise (minimum $35 \mathrm{~min}$, maximum $10 \mathrm{~h}$, average $4 \mathrm{~h}$ and $26 \mathrm{~min}$, noting that the mating duration often exceeded camera memory capacity and was thus underestimated; Fig. 1). Forty-two percent of evening matings lasted through most of the night (more than six hours).

Since there was no significant difference in spermatophore size between morning and evening matings ( $\mathrm{t}$-test: $\mathrm{t}=-1.708 \mathrm{df}=38, \mathrm{p}=0.096$ ), we suspect that transfer of material did not take place throughout the entire duration of such long nocturnal matings (see also Supplement 2). Therefore, we performed further statistical analyses excluding matings in excess of $3 \mathrm{~h}$ when using mating duration as a predictor of spermatophore mass, or when testing predictors of mating duration. Even after excluding these long matings, evening matings were on average longer ( $\mathrm{t}$-test: $\mathrm{t}=2.421, \mathrm{df}=48, \mathrm{p}=0.019$ ). For 
Fig. 1 Mating durations of Melanitis leda males with virgin females for the first up to the fifth mating of the male. While morning matings never exceeded three hours, many evening matings lasted until shortly before dawn. Note that many long nocturnal mating durations are underestimated for technical reasons

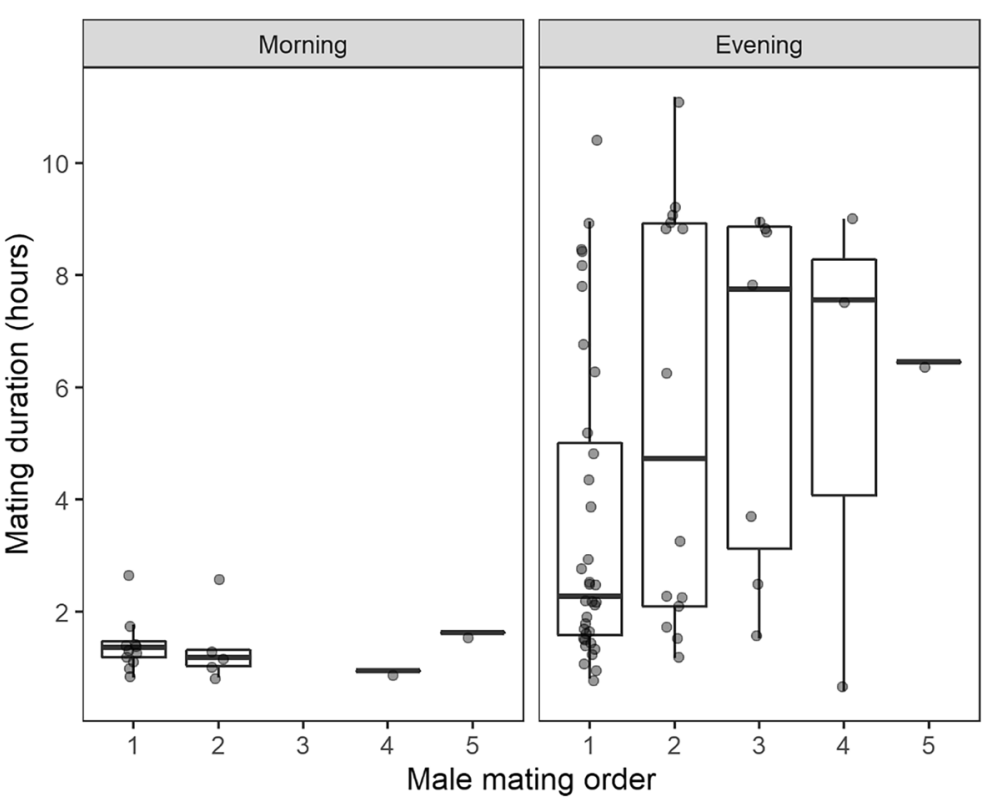

the matings that lasted less than $3 \mathrm{~h}$, we implemented GLM models that included mating period (morning vs. evening) along with one additional predictor and their interaction (male mating order, the time interval between matings, pupal mass, and male seasonal form). These potential predictors or their interaction with mating period never approached significance (results of models without interactions given in Table 1). Spermatophore mass was not predicted by mating duration (Regression: $\mathrm{F}_{1,10}=$ 2.21, $\mathrm{p}=0.171, \mathrm{~N}=11, \mathrm{R}^{2}=20 \%$; Fig. 2), unless one outlier was removed (Regression: $\mathrm{F}_{1,9}=10.67$, $\mathrm{p}=0.011, \mathrm{R}^{2}=57 \%$ ). The first spermatophore of a male tended to have a higher mass than later ones (average dry mass of first spermatophore $0.0018 \mathrm{mg}$, later ones $0.0012 \mathrm{mg}$., t-test between first and subsequent matings: $\mathrm{t}=2.377, \mathrm{df}=37, \mathrm{p}=0.023$; Fig. 3). Even when long matings were included, male seasonal form did not predict spermatophore mass (one way ANOVA: $\mathrm{F}_{1,32}=0.042, \mathrm{p}=0.958$, $\mathrm{N}=33$ ).

Mating Frequency in the Wild

Forty-one wild $M$. leda from the study population were dissected. Twelve females were not mated, 23 contained 1 spermatophore, and 6 had 2 spermatophores.
Observations on Mating Behavior

Precise quantitative behavioral observations were difficult to obtain because movements were rapid and transient, multiple males and females tended to be active in the cage at once, light levels were often low, and it is not possible to distinguish the sexes in flight with certainty (sex can only be ascertained after the butterflies have alighted and close inspection is possible). Nevertheless, we were able to note that at the start of the mating period, males flew towards perched butterflies and courted females. Males then often took up position with a clear view of the arena, such as on plants or on the knees, hands or nose of the observer. As females became more active, males would fly from their perch after females, or engage with other males in aerial combat in twirls (rapid motion in spirals). Courtship consisted of males positioned behind perched females and fluttering their wings rapidly for at most a few seconds. Females refused male advances by pointing their abdomens upwards or by flying away and settling elsewhere. Females occasionally twirled with males, which could be followed by a mating. Matings resulted when females perched on the cage wall or on a plant, and males approached from behind and, after fluttering their wings, curled their abdomens sideways ca. 180 degrees to make genital contact while the female sat still. In some instances, two males attempted to initiate copulation with the same female simultaneously, and in many instances males 
Table 1 Results of GLM analyses on M. leda mating durations of these that lasted less than $3 \mathrm{~h}$. Mating period = morning or evening, male mating order $=$ whether it was the first or second mating of the male, mating interval = time between first and second matings of a male in days, male pupal mass=pupal mass of males in grams, male forms refer to phenotypically plastic wing patterns that were compared to wet season forms

\begin{tabular}{lclll}
\hline Predictor & Estimate & s.e. estimate & $\mathrm{t}$ & $\mathrm{p}$ \\
\hline $\mathrm{N}=49, \mathrm{df}=44, \mathrm{R}^{2}=20 \%$ & & & \\
Intercept & 1.605 & 0.097 & 16.628 & $\mathbf{0 . 0 0 0}$ \\
mating period & 0.204 & 0.086 & 2.386 & $\mathbf{0 . 0 2 2}$ \\
male mating order & 0.010 & 0.095 & 0.101 & 0.920 \\
$\mathrm{~N}=16, \mathrm{df}=14, \mathrm{R}^{2}=12 \%$ & & & \\
Intercept & 1.836 & 0.392 & 4.689 & $\mathbf{0 . 0 0 0}$ \\
mating period & 0.196 & 0.096 & 2.053 & $\mathbf{0 . 0 4 8}$ \\
mating interval & -0.904 & 1.007 & -0.897 & 0.376 \\
$\mathrm{~N}=36, \mathrm{df}=34, \mathrm{R}^{2}=12 \%$ & & & \\
Intercept & 1.836 & 0.392 & 4.689 & $\mathbf{0 . 0 0 0}$ \\
mating period & 0.196 & 0.096 & 2.053 & $\mathbf{0 . 0 4 8}$ \\
male pupal mass & -0.904 & 1.007 & -0.897 & 0.376 \\
$\mathrm{~N}=36, \mathrm{df}=33, \mathrm{R}^{2}=13 \%$ & & & \\
Intercept & 1.545 & 0.103 & 14.959 & $\mathbf{0 . 0 0 0}$ \\
male intermediate form & -0.148 & 0.123 & -1.205 & 0.237 \\
male dry form & 0.029 & 0.145 & 0.198 & 0.844 \\
mating period & 0.202 & 0.100 & 2.013 & 0.052 \\
\hline
\end{tabular}

interfered with a courting pair by performing wing fluttering and pushing with their heads so that the pair could not copulate and the female flew off. On 3 occasions in the morning, males were noticed to be shivering as they were perched on a hand or nose. A video is provided showing twirling butterflies, courtship, and a mating (Supplement 1).

\section{Discussion}

We observed mating behavior in a South Indian population of M. leda in captivity, and measured mating duration and spermatophore size. We found that these butterflies have brief periods of mating behavior around sunrise and sunset, and that $42 \%$ of evening matings lasted through most of the night. Female M. leda are only moderately polyandrous and appear to exercise mate choice.

Most matings were initiated within a 15-minute time frame during both morning and evening observations. In contrast, Kemp (2002) did not report mating activity in the morning in Australia. Therefore, there may be differences among populations in the occurrence or relative frequency of morning and evening matings. Early morning mating behavior may be rare among butterflies (Freitas et al. 1997). Nevertheless, owl butterflies (Caligo idomenaeus) also show mating activity at dawn
Fig. 2 Relationship between mating duration and spermatophore mass for matings that lasted less than three hours. Spermatophore mass was not predicted by mating duration $(\mathrm{F}=$ $2.21, \mathrm{p}=0.171, \mathrm{~N}=11, \mathrm{R}^{2}=$ $20 \%$;), unless one outlier was removed (Regression: $\mathrm{F}=10.67$, $\mathrm{p}=0.011, \mathrm{~N}=10, \mathrm{R}^{2}=57 \%$; removing the large spermatophore from second shortest mating duration)

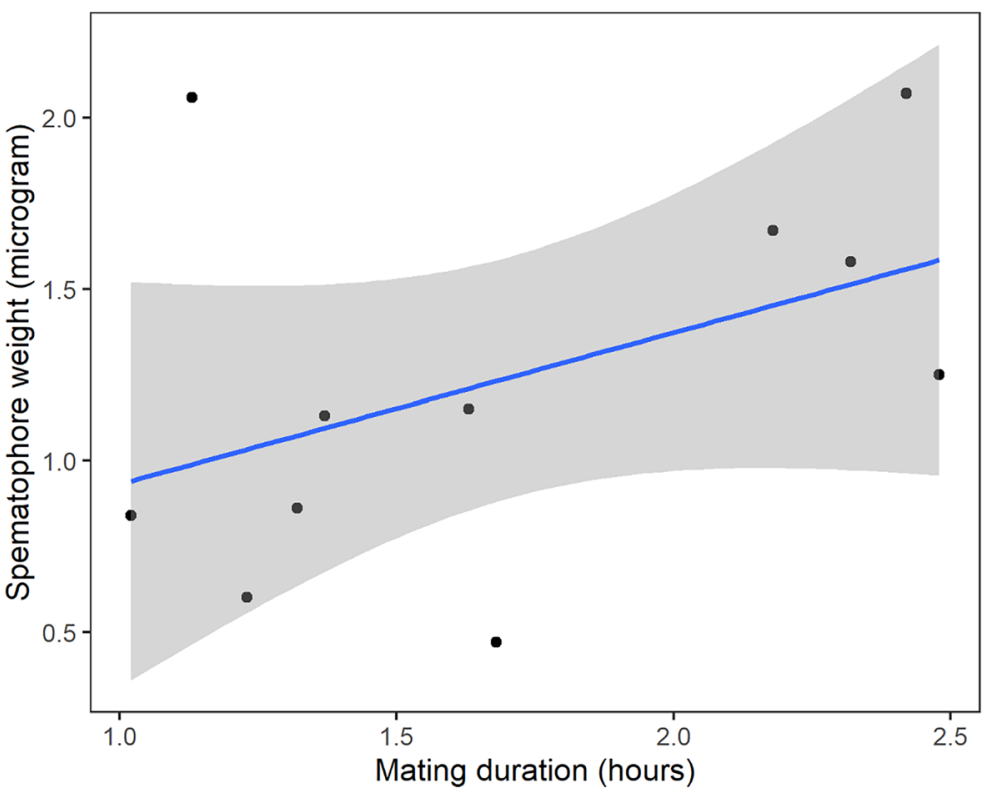


Fig. 3 Spermatophore dry mass per mating of individual male Melanitis leda butterflies, including long evening matings

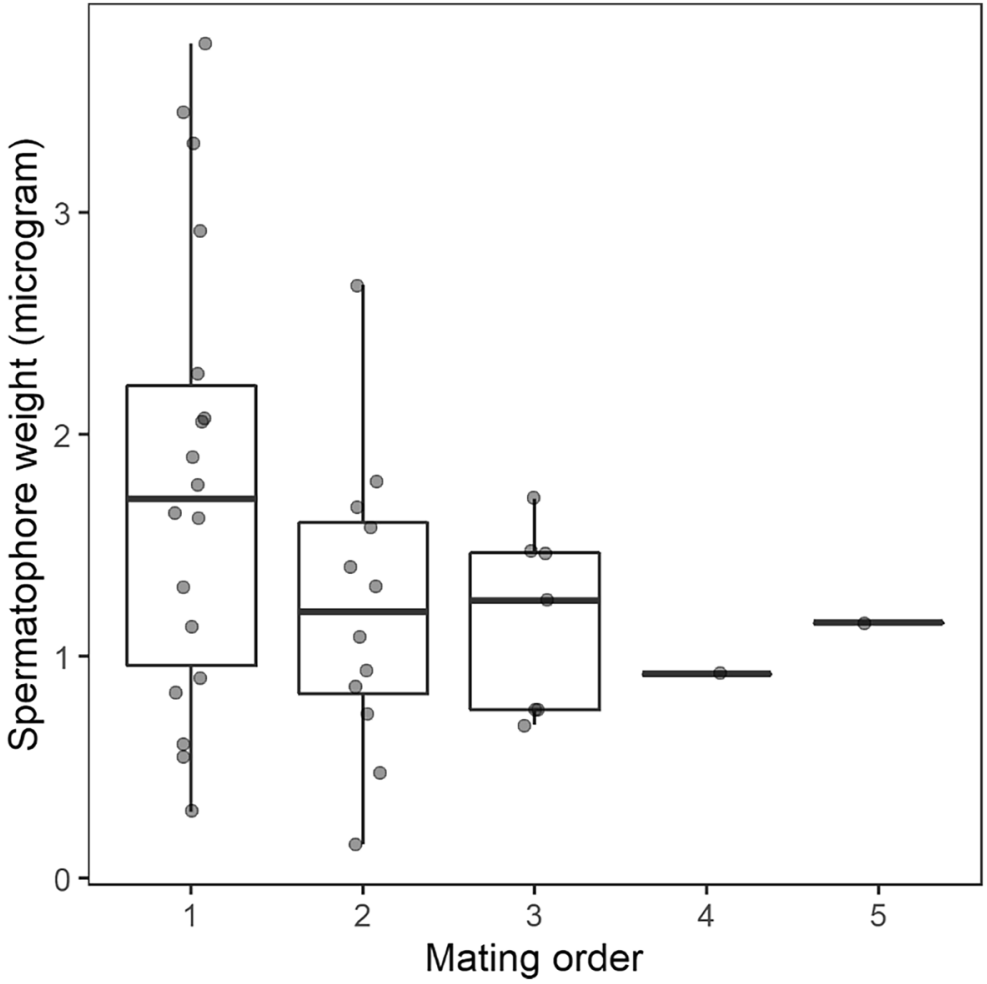

for only about $15 \mathrm{~min}$ (Freitas et al. 1997), and similar behavior might occur in other species of evening brown. We observed that M. leda butterflies can shiver in the morning, which is similar to owl butterflies (Srygley 1994), and hitherto unknown in this species. Shivering may allow butterflies to warm up and be active when the ambient temperature is too low for flight activity (Masters et al. 1988; Srygley 1994). Since shivering is energetically costly (Srygley 1994), females may be selected to prefer males that are able to compete when the ambient temperature is low. In addition, there may be selection for females to be receptive only during a short time-frame to promote competition among males. The timing and brevity of mating periods may also be selected by predators (suggested by Freitas et al. 1997) or to serve to avoid reproductive interference from other species that mate at different times of the day (suggested by DeVries et al. 2008).

The durations of morning matings were within the normal range recorded for satyrine butterflies (Molleman et al. 2004), but the long nocturnal matings were unexpected. Since such long nocturnal matings did not lead to heavier spermatophores, it seems unlikely that material is transferred throughout the entire mating. Perhaps such long matings carry little predation risk during the night, while copulating is risky during the day. When in copula, mobility can be greatly constrained so that couples are more susceptible to predation than single individuals (Magnhagen 1991; Almbro and Kullberg 2009). Because predation pressure may be higher during the day compared to the night (Seifert et al. 2016), butterflies mating after sunset might experience relaxed predation pressure against long matings compared to those mating in the morning. Furthermore, these butterflies are not active during the night and thus nocturnal mating does not strain their activity budget. Mate guarding may be an unsatisfactory explanation in this case, because there is no mate competition during the night and females do not normally mate in quick succession (pilot study and our spermatophore counts). Nevertheless, perhaps long nocturnal matings do influence female behavior. Nocturnal mating has also been documented in monarch butterflies in their winter roosts, where coupling takes place during the day, but sperm transfer only starts at night, which probably is a form of mate guarding (Svärd and Wiklund 1988). From a mechanistic perspective, we hypothesize that butterflies follow their diel activity pattern and fall asleep while in copula, and uncouple as they wake up in the morning (Helfrich-Förster 2018). We suspect that 
M. leda butterflies often remain in copula during the night because there is neither cost nor benefit of them doing anything else.

Mating duration (of first mating) might be expected to correlate with spermatophore size because transfer of material costs time. Because there was no significant difference in spermatophore mass between morning and evening matings, we suppose that the full duration of the long nocturnal matings does not represent transfer of material. We therefore limited this analysis to observations of matings lasting less than $3 \mathrm{~h}$, thus allowing only a sample size of 11 . One data point showed a large spermatophore for a brief mating ( $1 \mathrm{~h}$ and $10 \mathrm{~min}$ ), being about twice the mass of spermatophores of other matings that lasted less than two hours. Only if we exclude this outlier, do we find that longer matings resulted in larger spermatophores. Therefore, more data are needed to establish whether or not there is a correlation between mating duration (of the first mating) and spermatophore size in M. leda.

We found that males did transfer slightly smaller spermatophores during subsequent matings (when long matings were included), similar to many other butterflies (Dewsbury 1982; Oberhauser 1988, 1992; Svärd and Wiklund 1986). However, mating duration was not correlated with mating order (excluding nocturnal matings that exceeded three hours), while in butterflies subsequent matings of a male are often longer and sometimes shorter than the first mating (Svärd and Wiklund 1986; Bissondath and Wiklund 1996; Oberhauser 1988, 1992; Molleman et al. 2004). We found no significant relationships between seasonal form, body size, or mating interval and spermatophore size or mating duration, but note that our sample sizes were small.

Monandrous butterfly species tend to have smaller spermatophores than do polyandrous species (Svärd and Wiklund 1989). Since females of M. leda usually mate only once or twice, we may expect quite small spermatophores in this species. Indeed, the spermatophores we found were smaller than those of highly polyandrous species (Oberhauser 1989; Karlsson 1998). If females mate only once, males may also have limited chances to mate multiply, and may thus be selected to invest most of their resources in their first mating, impairing their ability to mate again (Wedell et al. 2002; Molleman et al. 2004). Nevertheless, M. leda males were able to mate multiply even within the same day. This may be expected because the nutrient investment in spermatophores may be small (suggested by low mass). In our experiments, females sometimes twirled with males before courtship, but there are too few observations from the wild to determine if this also occurs in nature. Such male-female twirling may indicate that females can use twirling as a means to assess male quality. We confirmed that interference among males can be part of the male mating strategy (one similar observation in Kemp 2002). Pliske (1975) also observed such interference in the monarch butterfly in captivity so that the density of butterflies had to be limited to 40 to observe courtship behaviors. Although interfering males did not succeed in mating with females directly, they were successful in breaking up the courtship of others, so that these females would remain receptive. More precise ethological observations could be obtained using fewer individuals in larger cages, clearly marked sexes (e.g. using males and females of different seasonal forms reciprocally), and night vision video recordings.

Our results suggest that in $M$. leda, males compete mainly through the territorial defense that was studied by Kemp $(2002,2003)$ and possibly courtship, and to a lesser extent through providing large spermatophores to females, or sperm competition. Females appear to exert some control over the mating system because receptive females are known to actively entice males by flying conspicuously near male territories (Kemp 2002), females may test males by engaging in twirling similar to male-male competition (this study), and refuse copulations by pointing their abdomens upwards (this study). Females may choose males based on male fighting ability during cool parts of the day, and perhaps based on wing-fluttering performance during courtship (which might fan male pheromones over the female). Since during courtship the male is directly behind the female, and courtship takes place during twilight, females are not likely to use visual cues when assessing potential mates.

In conclusion, we found that M. leda in South India (1) performs mating behavior for short periods of time around sunrise and sunset, possibly facilitated by shivering, (2) evening matings can last extraordinarily long without resulting in larger spermatophores, (3) males can mate multiply, even twice during the same day, (4) subsequent matings of a male tend to yield spermatophores of slightly lower mass than the first but are of similar duration, (5) males actively interfere in courtship of others, (6) receptive females may twirl with males and can refuse copulation, and (7) females usually mate once or twice during their life time. 
Acknowledgements We thank Harshad Mayekar for advice on rearing $M$. leda and sexing pupae, and building the shelters in which we constructed the large cages. We are grateful to Jisha Vijaykumar and Vignesh $\mathrm{O}$. for help with growing plants, rearing larvae, and sexing and weighing pupae.

Authors' Contributions Freerk Molleman was partly responsible for study design and data collection, analyzed the data and wrote the first draft of the MS. Sridhar Halali was partly responsible for study design, data collection, graphical representation, literature review and contributed to MS writing. Ullasa Kodandaramaiah participated in data interpretation and MS writing. All authors read and approved the final manuscript.

Funding This work was funded through intra-mural funds from IISER Thiruvananthapuram and a grant from the Department of Science and Technology, Government of India to Ullasa Kodandaramaiah (INSPIRE Faculty Award number DST/INSPIRE/04/2013/000476).

Data Availability The data are available upon request.

\section{Compliance with Ethical Standards}

\section{Conflicts of Interest/Competing Interests Not applicable.}

Code Availability Not applicable.

Open Access This article is licensed under a Creative Commons Attribution 4.0 International License, which permits use, sharing, adaptation, distribution and reproduction in any medium or format, as long as you give appropriate credit to the original author(s) and the source, provide a link to the Creative Commons licence, and indicate if changes were made. The images or other third party material in this article are included in the article's Creative Commons licence, unless indicated otherwise in a credit line to the material. If material is not included in the article's Creative Commons licence and your intended use is not permitted by statutory regulation or exceeds the permitted use, you will need to obtain permission directly from the copyright holder. To view a copy of this licence, visit http://creativecommons.org/licenses/by/4.0/.

\section{References}

Allen CE, Zwaan BJ, Brakefield PM (2011) Evolution of sexual dimorphism in the Lepidoptera. Annu Rev Entomol 56:445464

Almbro M, Kullberg C (2009) The downfall of mating: the effect of mate-carrying and flight muscle ratio on the escape ability of a pierid butterfly. Behav Ecol Sociobiol 63:413

Andersson M (1994) Sexual selection. Princeton University Press, Princeton
Andersson M, Simmons LW (2006) Sexual selection and mate choice. TREE 21:296-302

Bergman B, Gotthard K, Wiklund C (2011) Mate acquisition by females in a butterfly: the effects of mating status and age on female mate-locating behavior. Anim Behav 81:225-229

Bissoondath CJ, Wiklund C (1995) Protein content of spermatophores in relation to monandry/polyandry in butterflies. Behav Ecol Sociobiol 37:365-371

Bissoondath CJ, Wiklund C (1996) Effect of male mating history and body size on ejaculate size and quality in two polyandrous butterflies, Pieris napi and Pieris rapae (Lepidoptera: Pieridae). Funct Ecol 10:457-464

Boggs CL (1981) Selection pressures affecting male nutrient investment at mating in heliconiine butterflies. Evolution 35: 931-940

Boggs CL, Gilbert LE (1979) Male contribution to egg production in butterflies: evidence for transfer of nutrients at mating. Science 206:83-84

Brakefield PM (1987) Tropical dry and wet season polyphenism in the butterfly Melanitis leda (Satyrinae): phenotypic plasticity and climatic correlates. Biol J Linn Soc 31:175-191

Burns JM (1968) Mating frequency in natural population of skippers and butterflies as determined by spermatophore counts. PNAS 61:852-859

Cannon RJ (2019) Courtship and mating in butterflies. CABI publishing, Boston

Common IFB, Waterhouse DF (1981) Butterflies of Australia. Angus and Robertson, Sydney

Costanzo K, Monteiro A (2007) The use of chemical and visual cues in female choice in the butterfly Bicyclus anynana. Proc Biol Sci 274:845-851

DeVries PJ, Austin GT, Martin NH (2008) Diel activity and reproductive isolation in a diverse assemblage of Neotropical skippers (Lepidoptera: Hesperiidae). Biol J Linn Soc 94:723-736

Dewsbury DA (1982) Ejaculate cost and male choice. Am Nat 119:601-610

Freitas AVL, Benson WW, Marini-Filho OJ, de Carvalho RM (1997) Territoriality by the dawn's early light: the Neotropical owl butterfly Caligo idomenaeus (Nymphalidae: Brassolinae). J Res Lepid 34:14-20

Halali D, Krishna A, Kodandaramaiah U, Molleman F (2019) Lizards as predators of butterflies: shape of wing damage and effects of eyespots. J Lepid Soc 73:78-86

Helfrich-Förster C (2018) Sleep in insects. Annu Rev Entomol 63: 69-86

Kaitala A, Wiklund C (1994a) Polyandrous females forage for matings. Behav Ecol Sociobiol 35:385-388

Kaitala A, Wiklund C (1994b) Female mate choice and mating costs in the polyandrous butterfly Pieris napi (Lepidoptera: Pieridae). J Insect Behav 8:355-363

Karlsson B (1995) Resource allocation and mating systems in butterflies. Evolution 49:955-961

Karlsson B (1998) Nuptial gifts, resource budgets, and reproductive output in a polyandrous butterfly. Ecology 79:29312940

Kemp DJ (2002) Visual mate-searching behaviour in the evening brown butterfly, Melanitis leda (L.)(Lepidoptera: Nymphalidae). Aust Entomol 41:300-305 
Kemp DJ (2003) Twilight fighting in the evening brown butterfly, Melanitis leda (L.) (Nymphalidae): age and residency effects. Behav Ecol Sociobiol 54:7-13

Kemp DJ (2007) Female butterflies prefer males bearing bright iridescent ornamentation. Proc R Soc Lond B Biol Sci 274: 1043-1047

Kemp DJ, Wiklund C (2001) Fighting without weaponry: a review of male-male contest competition in butterflies. Behav Ecol Sociobiol 49:429-442

Kunte K (2000) India, a Lifescape: Butterflies of Peninsular India. Universities Press, Hyderabad

Larsen TB (1991) The Butterflies of Kenya and their Natural. History Oxford University Press, Oxford

Magnhagen C (1991) Predation risk as a cost of reproduction. Trends Ecol Evol 6:183-186

Masters AR, Malcolm SB, Brower LP (1988) Monarch butterfly (Danaus plexippus) thermoregulatory behavior and adaptations for overwintering in Mexico. Ecology 69:458-467

Mitra C, Reynoso E, Davidowitz G, Papaj D (2016) Effects of sodium puddling on male mating success, courtship and flight in a swallowtail butterfly. Anim Behav 114:203-210

Molleman F, Zwaan BJ, Brakefield PM (2004) The effect of male sodium diet and mating history on female reproduction in the puddling squinting bush brown Bicyclus anynana (Lepidoptera). Behav Ecol Sociobiol 56:404-411

Molleman F, Grunsven RH, Liefting M, Zwaan BJ, Brakefield PM (2005) Is male puddling behaviour of tropical butterflies targeted at sodium for nuptial gifts or activity? Biol J Linn Soc 86:345-361

Molleman F, Halali S, Kodandaramaiah U (2020) Oviposition preference maximizes larval survival in the grass-feeding butterfly Melanitis leda (Lepidoptera: Nymphalidae). Eur J Entomol 117:1-17

Oberhauser KS (1988) Male monarch butterfly spermatophore mass and mating strategies. Anim Behav 36:1384-1388

Oberhauser KS (1989) Effects of spermatophores on male and female monarch butterfly reproductive success. Behav Ecol Sociobiol 25:237-246

Oberhauser KS (1992) Rate of ejaculate breakdown and intermating intervals in monarch butterflies. Behav Ecol Sociobiol 31:367-373

Parsons M (1999) Butterflies of Papua New Guinea: Their Systematics and Biology. Academic Press, London

Pivnick KA, McNeil JN (1987) Puddling in butterflies: sodium affects reproductive success in Thymelicus lineola. Physiol Entomol 12:461-472

Pliske TE (1975) Courtship behavior of the monarch butterfly, Danaus plexippus L. Ann Entomol Soc Am 68:143-151
Prudic KL, Jeon C, Cao H, Monteiro A (2011) Developmental plasticity in sexual roles of butterfly species drives mutual sexual ornamentation. Science 331:73-75

R Core Team (2017) R: A language and environment for statistical computing. R Foundation for Statistical Computing, Vienna

Rutowski RL (1980) Courtship solicitation by females of the checkered white butterfly, Pieris protodice. Behav Ecol Sociobiol 7:113-117.

Rutowski RL (1991) The evolution of male mate-locating behavior in butterflies. Am Nat 138:1121-1139

Rutowski RL, Gilchrist GW (1985) Copulation in Colias eurytheme (Lepidoptera: Pieridae): patterns and frequency. J Zool Soc Lond 209:15-124

Seifert CL, Schulze CH, Dreschke TC, Frötscher H, Fiedler K (2016) Day vs. night predation on artificial caterpillars in primary rainforest habitats: an experimental approach. Entomol Exp Appl 158:54-59

Shuker DM, Simmons LW (eds) (2014) The evolution of insect mating systems. Oxford University Press, New York

Srygley RB (1994) Shivering and its cost during reproductive behaviour in Neotropical owl butterflies, Caligo and Opsiphanes (Nymphalidae: Brassolinae). Anim Behav 47: 23-32

Svärd L, Wiklund C (1986) Different ejaculate delivery strategies in first versus subsequent matings in the swallowtail butterfly Papilio machaon L. Behav Ecol Sociobiol 18:325-330

Svärd L, Wiklund C (1988) Prolonged mating in the monarch butterfly Danaus plexippus and nightfall as a cue for sperm transfer. Oikos 51:351-354

Svärd L, Wiklund C (1989) Mass and production rate of ejaculates in relation to monandry/polyandry in butterflies. Behav Ecol Sociobiol 24:395-402

TIBCO Software Inc (2017) Statistica (data analysis software system), version 13. http://statistica.io

Välimäki P, Kaitala A (2006) Does a lack of mating opportunities explain monandry in the green-veined white butterfly (Pieris napi)? Oikos 115:110-116

Watanabe M (2016) Sperm Competition in Butterflies. Ecological Research Monographs. Springer, Tokyo

Wedell N, Wiklund C, Cook PA (2002) Monandry and polyandry as alternative lifestyles in a butterfly. Behav Ecol 13:450-455

Wickman PO (1992) Sexual selection and butterfly design: a comparative study. Evolution 46:1525-1536

Wiklund C, Gotthard K, Nylin S (2003) Mating system and the evolution of sex-specific mortality rates in two nymphalid butterflies. Proc R Soc Lond B 270:1823-1828 